\title{
The Utilization and Translocation by Micro-organisms of Carbon-14 Derived from the Decomposition of Plant Residues in Soil
}

\author{
By ERNA GROSSBARD* \\ The Grassland Research Institute, Hurley, Maidenhead, Berkshire, and \\ The Hartley Botanical Laboratories, University of Liverpool
}

(Accepted for publication I4 April I97I)

\begin{abstract}
SUMMAR Y
The utilization and translocation of ${ }^{14} \mathrm{C}$ by micro-organisms, especially fungi, was shown to occur during the decomposition of labelled plant residues in agar cultures and in soil. Utilization was demonstrated by the evolution of ${ }^{14} \mathrm{CO}_{2}$ and by autoradiograms that showed ${ }^{14} \mathrm{C}$ within micro-organisms. Translocation was indicated by labelled structures occurring on coverslips at a distance from the substrate, and by the labelling of sclerotia which had accumulated ${ }^{14} \mathrm{C}$ preferentially nearly $\mathrm{I} \mathrm{cm}$. from the plant residues. Rhizoctonia solani, Trichoderma $\mathrm{sp}$. and Streptomyces flavovirens, shown to be cellulolytic on cotton cellulose agar, were similarly active in agar and soil cultures containing radioactive plant residues. Labelled structures of Fusarium spp., Rhizoctonia spp., Humicola grisea, Xylaria spp. and fungi with non-sporing dark mycelia were detected in non-sterile soil during the later stages of the decomposition of the labelled plant residues when a marked fall in carbon content was occurring. The autoradiographic technique employed here enables organisms that probably act as primary agents in the degradation of plant residues to be distinguished from those that do not.
\end{abstract}

\section{INTRODUCTION}

The utilization of a carbon compound by a pure culture of a micro-organism can readily be demonstrated by providing the compound as the sole source of carbon. In the soil such a utilization is, however, difficult to measure or even to demonstrate since soil contains a mixed microbial population and a variety of carbon compounds. The participation of a single species in the degradation of, for instance, a specific plant material and the utilization of its breakdown products cannot be readily elucidated. Garrett(1962), however, demonstrated the decomposition of cellulose by one species in soil through observing that the addition of filter paper increased the growth rate of Rhizoctonia solani Kühn inoculated into growth tubes containing non-sterile soil.

The use of degradation products may facilitate the extension of mycelium through soil by translocation of these nutrients through fungal hyphae during growth from one food base to another. Many studies have been made on translocation in fungi (Buller, I933; Schütte, 1956; Grossbard, 1958; Grossbard \& Stranks, 1959; Lucas, 1960; and others as reviewed by Hill, I965, and Wilcoxson \& Sudia, 1968) but most investigations were confined to pure cultures on agar media. The present paper is an account of a study of the utilization and translocation by micro-organisms of ${ }^{14} \mathrm{C}$ derived from the decomposition of labelled plant residues in agar cultures and in sterile and non-sterile soil, and has employed labelled plant residues and autoradiography.

* Present address: ARC Weed Research Organization, Begbroke Hill, Yarnton, Oxford, OX 5 I PF. 


\section{METHODS}

Organisms and routine culture. Rhizoctonia solani Kühn [syn. Pellicularia fllamentosa (Pat.) Rogers] was kindly supplied by Dr S. D. Garrett; Trichoderma sp. and Streptomyces flavovirens Waksman were isolated by D. M. Hall from a grassland soil at Hurley, Berkshire. The two fungi were maintained on Difco potato-dextrose agar and the $S$. flavovirens on Hungate's cotton-wool agar (Skinner, 1960).

${ }^{14} \mathrm{C}$ labelled substrates. Experiments were carried out in agar cultures, in sterile and nonsterile soil. Labelled plant fragments or residues were incorporated into the three substrates to serve as a source of carbon.

(I) In experiments with agar media and sterile soil insoluble residues of the roots of ${ }_{1}^{14} \mathrm{C}$ labelled tobacco plants, extracted with ethanol (Catch \& Evans, 1960), were used. The residues were washed with water to remove starch and contained probably crude celluloses to a large extent. The total activity was $127 \mu \mathrm{Ci} / \mathrm{g}$. residue. To the basal agar medium or soil $95 \mathrm{mg}$. was added to give a final activity of $0.6 \mu \mathrm{Ci} / \mathrm{g}$. agar or soil. (2) In experiments with non-sterile soil all plants were uniformly labelled and used without any extraction procedure: (a) fragments cut from intact leaves of rye (Secale cereale) supplied by Professor Schwarting (Paul, Scully \& Schwarting, 1960) spec. act. $0.42 \mu \mathrm{Ci} / \mathrm{g}$. C; (b) pellets prepared from powdered leaves of rye grass (Lolium perenne) (Grossbard, 1969) spec. act. $35 \mu \mathrm{Ci} / \mathrm{g} . \mathrm{C}$ and cocksfoot (Dactylis glomerata) spec. act. $34 * 4 \mu \mathrm{Ci} / \mathrm{g}$. C.

Experiments with agar media. Ten $\mathrm{ml}$. of basal medium of the following composition $(\%, \mathrm{w} / \mathrm{v})$ were placed into I25 ml. screw-capped bottles: $\mathrm{NH}_{4} \mathrm{NO}_{3}, 0 \cdot \mathrm{I} ; \mathrm{MgSO}_{4} \cdot 7 \mathrm{H}_{2} \mathrm{O}$, $0.03 ; \mathrm{FeSO}_{4} \cdot 7 \mathrm{H}_{2} \mathrm{O}, 0.0025$; agar, $\mathrm{I} \cdot 2$; dist. $\mathrm{H}_{2} \mathrm{O}$. The medium for the fungi was adjusted to give after autoclaving a $\mathrm{pH}$ of 4.9 by the addition of $0.13 \%$ of $\mathrm{K}_{2} \mathrm{HPO}_{4}$ and $3.4 \%$ $\mathrm{KH}_{2} \mathrm{PO}_{4}$, and the medium for Streptomyces flavovirens to $\mathrm{pH} 7 \cdot \mathrm{I}$ by adding 3.27 and $0.85 \%$ respectively. Another $10 \mathrm{ml}$. of the basal medium were mixed with the tobacco residues and poured over the ro $\mathrm{ml}$. mineral agar in the bottle. A sterile bijou bottle containing $3 \mathrm{ml}$. of $2 \mathrm{~N}-\mathrm{NaOH}$ was pushed into the agar before solidification to absorb the $\mathrm{CO}_{2}$ evolved during the growth of the culture.

Experiments with sterile soil. Twenty g. of grassland soil from Hurley, Berkshire, were placed into $125 \mathrm{ml}$. screw-capped bottles and the moisture content of the soil adjusted to $75 \mathrm{~cm}$. water suction $(0.07 \mathrm{~atm}$.). The tobacco root residues were mixed with the soil in a deliberately heterogenous manner. The soils were then autoclaved for $30 \mathrm{~min}$. at $\mathrm{I} \mathrm{kg} . / \mathrm{cm} .{ }^{2}$. As in the agar culture a sterile container with $\mathrm{NaOH}$ was inserted aseptically into the soil.

Experiments with non-sterile soil. The plant material was placed on the surface of soil (Grossbard, 1969). (a) The base of a Petri dish was filled with soil from the Ainsdale dunes, Lancashire, and the moisture content adjusted as for sterile soil. Fragments cut from intact leaves of rye were placed in the centre. Containers with $\mathrm{NaOH}$ were placed close to the Petri dishes and both covered with a tall plastic box during incubation. (b) Square Perspex containers were filled with soil from the Botanic Gardens at Ness, Cheshire, and pellets of powdered rye grass or cocksfoot placed in the centre and the soils treated as in (a).

Measurement of cellulolytic activity. Activity of the three test organisms was measured in terms of the areas of clearing in $\mathrm{mm}^{2}$ on Hungate's cotton cellulose medium (Skinner, 1960; Grossbard \& Hall, 1962). For micro-organisms isolated in this work the method of Eggins \& Pugh (1962) was employed.

Measurement of ${ }^{14} \mathrm{CO}_{2}$. The radioactivity of the ${ }^{14} \mathrm{CO}_{2}$ evolved in the sterile soil cultures was estimated to ascertain only whether or not the plant residues had been broken down rather than to measure accurately the amount of decomposition. The contents of the bijou bottles 
were precipitated by the addition of an excess of a solution containing $\mathrm{I}$ N-barium chloride and I N-barium hydroxide and the activity of the precipitate counted by means of a G-M tube with a thin end window by the method of Edelman, Shibko \& Keys (I959).

Autoradiography. (a) Autoradiograms of microbial structures teased out on microscope slides or growing over coverslips and subsequently fixed to microscope slides were prepared by the stripping-film technique (Pelc, 1956; Grossbard, 1958, 1962; Rogers, 1967). A section of film cut from an A.R. Io Kodak fine grain autoradiographic stripping plate was floated in a bath of distilled water at $24^{\circ}$ for 2 to $3 \mathrm{~min}$. Each microscope slide was coated with the section of film, dried in a light-proof tower in a stream of cool air and then placed at $1^{\circ}$ for at least 2 weeks in a light-proof box with a container of calcium chloride for additional drying. The film was developed by placing the slides in a D I 9 developer for $5 \mathrm{~min}$. and by fixing in a FX 40 fixer to which the appropriate hardener had been added (chemicals from Kodak); all solutions were maintained at $18^{\circ}$. This low temperature and the addition of a hardener are especially important in preparations where a coverslip is placed on a microscope slide because of the greater danger of the film slipping off during processing. The films were then dried in a drying tower in a stream of cold air. Processing renders the film transparent and it can be observed under the microscope either unstained or stained with malachite green or crystal violet. Silver grains were counted on photomicrographs of the autoradiograms prepared under standardized conditions on roll film in a plate camera with an appropriate adapter, rather than directly under the microscope according to standard practice. All fields (to a maximum of 20 ) containing labelled spores were photographed and the total number of spores and grains per field counted. Photomicrographs were also made of preparations from soils without labelled plant residues to provide a background count which was deducted from the grain counts of the labelled preparations. The mean number of grains per spore was then calculated. $(b)$ Autoradiograms of the soil surface in vessels containing non-sterile soil and plant residues were made by placing an X-ray film (Ilford Industrial G) over a Melinex (polyester) sheeting covering the soil surface. The soils were then placed for 2 weeks in a light-proof box at $1^{\circ}$ or $25^{\circ}$ (Grossbard, I969).

\section{Pure cultures}

RESULTS

The relative ability of the three test organisms to decompose cotton-wool cellulose was assessed; all three were cellulolytic and Rhizoctonia solani was the most active.

The uptake by micro-organisms of the ${ }^{14} \mathrm{C}$ compounds derived from the decomposition of the labelled plant residues and the translocation of the former through the growing hyphae was shown by autoradiography. Material for this purpose was obtained from agar and soil cultures.

Pure cultures on agar media. Agar media containing labelled plant residues or unlabelled controls were inoculated with the three test organisms and incubated for 2 weeks at $25^{\circ}$. Treatments were in triplicate and the experiment repeated three times. A portion of the surface mycelium was scraped off and teased out in a drop of $0.5 \%$ gelatin on a microscope slide previously dipped in a mixture of $0.5 \%$ gelatin and $0.05 \%$ chrome alum to improve the adhesion of the stripping film. Another series of agar cultures was set up in triplicate and four coverslips were inserted into the surface of the agar in each bottle at an angle of $45^{\circ}$ to $60^{\circ}$, prior to inoculation with the three test organisms. Before insertion, the coverslips were dipped in $0.5 \%$ gelatin and sterilized by ultraviolet radiation for $15 \mathrm{~min}$. The coverslips served as a surface for growth of the test organisms and facilitated the preparation of a good 

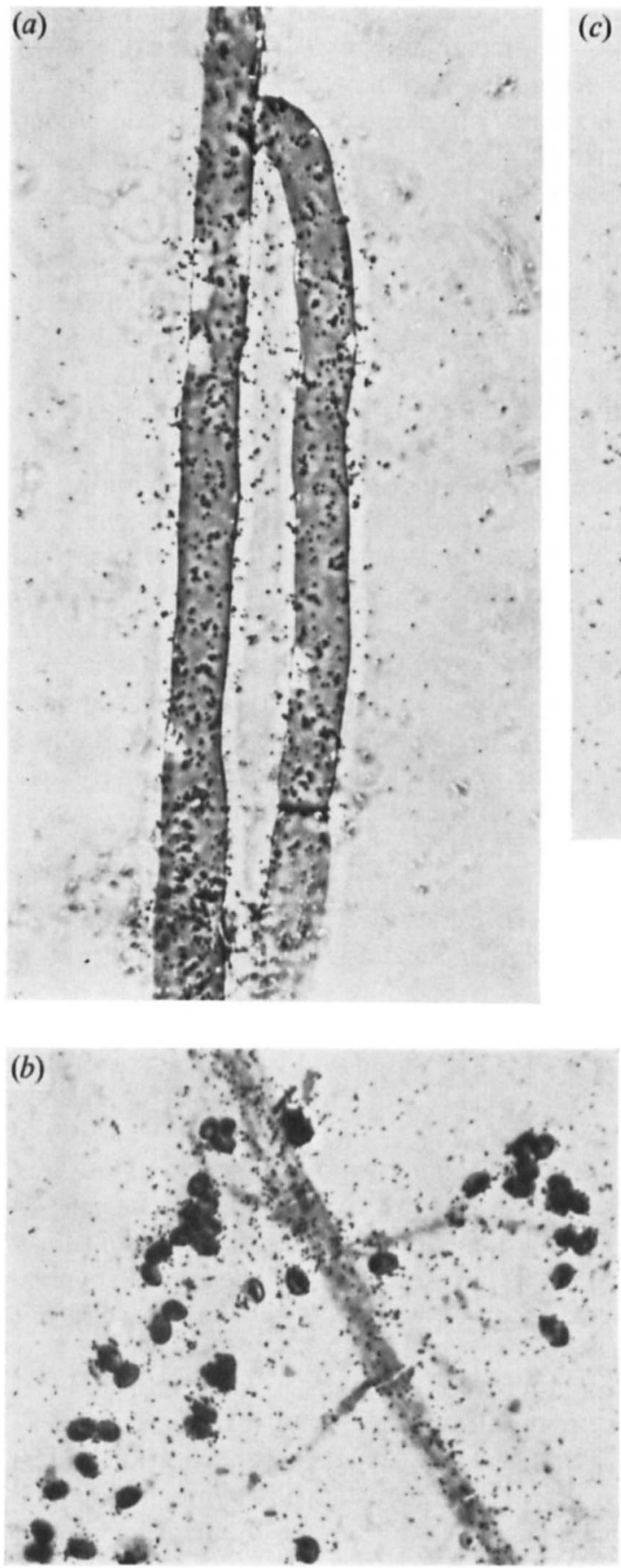
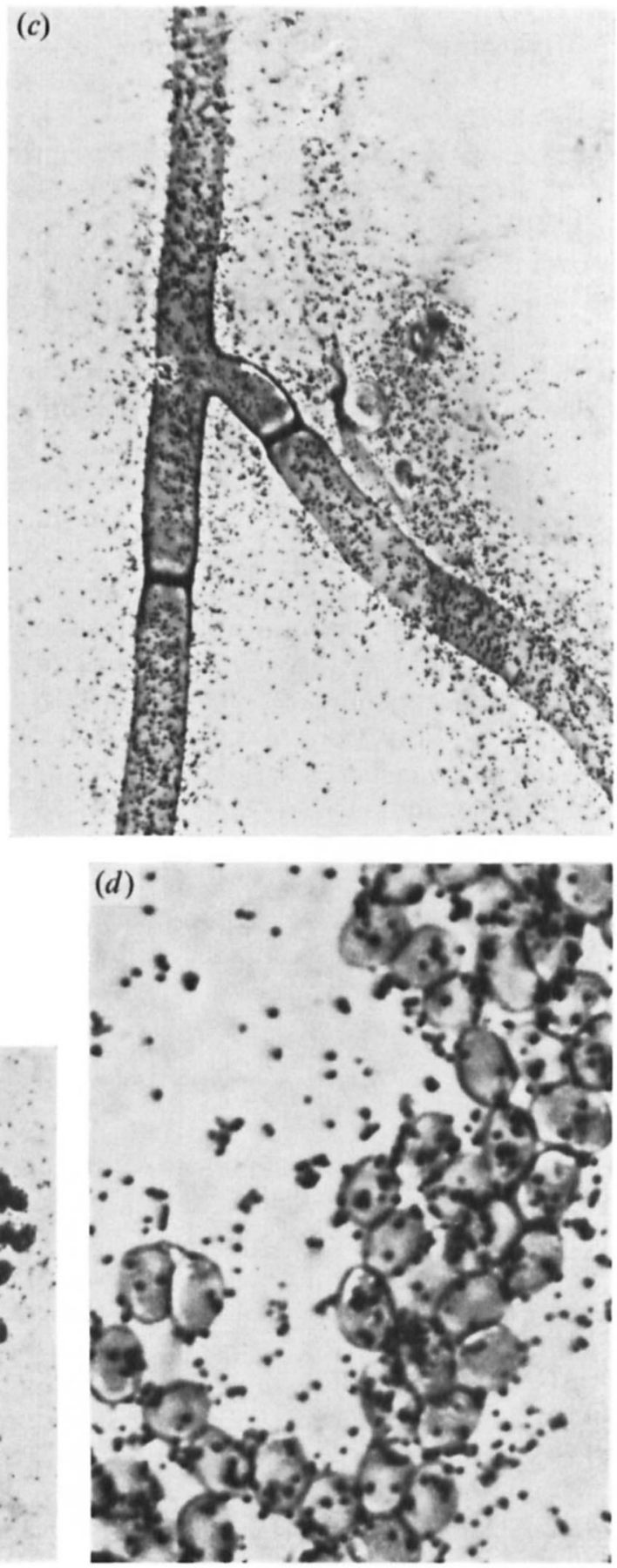

Plate I

Photomicrographs of coverslip autoradiograms

(a) Rhizoctonia solani grown on an agar medium. $\times$ I000.

(b) Trichoderma sp. grown on an agar medium. $\times 900$.

(c) Rhizoctonia solani grown in sterile soil. $\times 1100$.

(d) Trichoderma sp. grown in sterile soil, conidia. $\times 2200$. 
autoradiogram in view of the relatively low degree of absorption of the $\beta$-particles by the thin layer of mycelium formed over the coverslips. Coverslips were removed and replaced by a new set after incubation for 14 days at $25^{\circ}$; the alkali was also renewed. After examination for the presence of growth each coverslip was fixed in a drop of glycerine jelly to a microscope slide coated with gelatin and chrome alum; the coverslip was mounted with the side with most microbial growth facing upwards. The slides from both series were treated with u.v. radiation and an autoradiogram prepared.

The autoradiograms of mycelium removed from the agar surface as well as those of the coverslips of cultures of the test organisms show the scatter of grains of metallic silver above the microbial structures ( $\mathrm{Pl}$. I $a, b)$. These grains, caused by ionizing radiation from disintegrating ${ }^{14} \mathrm{C}$ atoms within the microbial cells, are evidence of the utilization by the microorganisms of material from the labelled substrate since it was the sole source of carbon in the agar media. The coverslip preparations also indicate the translocation of ${ }^{14} \mathrm{C}$. The mycelium on the coverslips could have become radioactive only by the transport of ${ }^{14} \mathrm{C}$ constituents from the plant residues contained in the agar substrate below. Contamination of the coverslip by ${ }^{14} \mathrm{CO}_{2}$ is unlikely since it was adsorbed by the $\mathrm{NaOH}$ in the bijou bottles.

Hyphae of Rhizoctonia showed the greatest grain density (Pl. I $a$ ). The conidia of Trichoderma were more heavily labelled than were the hyphae (Pl. $\mathrm{I} b$ ).

Mycelium of Streptomyces removed from the surface of agar cultures was labelled but coverslip preparations bore little growth. However, the structures that were detected were radioactive.

\section{Pure cultures inoculated into sterile soil}

Autoradiography. Four gelatin-coated coverslips were inserted into the soil. After inoculation with the test organisms the soils were weighed and incubated at $25^{\circ}$. Coverslips and $\mathrm{NaOH}$ were removed and replaced by fresh sets at irregular intervals, the moisture content was readjusted when necessary and incubation maintained for up to 2 years. Replication was similar to that for agar cultures. Autoradiograms of the coverslips were prepared as for agar cultures after careful removal of most of the soil particles by gentle suction or with a camel-hair brush. The autoradiograms of all three test organisms gave images similar to those of the agar cultures (Pl. I $c, d$ and Pl. 2a). The hyphae of Rhizoctonia (Pl. I $c$ ) were again more labelled than those of Trichoderma but the conidia of the latter were strongly labelled (PI. I $d$ ). Grain counts of the conidia were made after various periods of incubation. With the exception of the last period of 48 weeks the average count did not differ significantly with time of incubation (Table I).

On coverslip cultures of Streptomyces only restricted growth could be detected; some spore chains were more clearly labelled than the hyphae (PI. 2a).

The marked radioactivity of the test organisms, especially of the fungi, demonstrates that in sterile soil utilization and translocation of ${ }^{14} \mathrm{C}$ from the degradation of labelled residues occur in a manner similar to that on agar media.

Measurement of ${ }^{14} \mathrm{CO}_{2}$. The decomposition of labelled plant residues by the three test organisms was confirmed by the evolution of radioactive $\mathrm{CO}_{2}$ (Table 2). Most of the radioactivity disappeared in the first 6 weeks, less in the following 34 weeks, and there was no detectable activity after 72 weeks. 
E. GROSSBARD
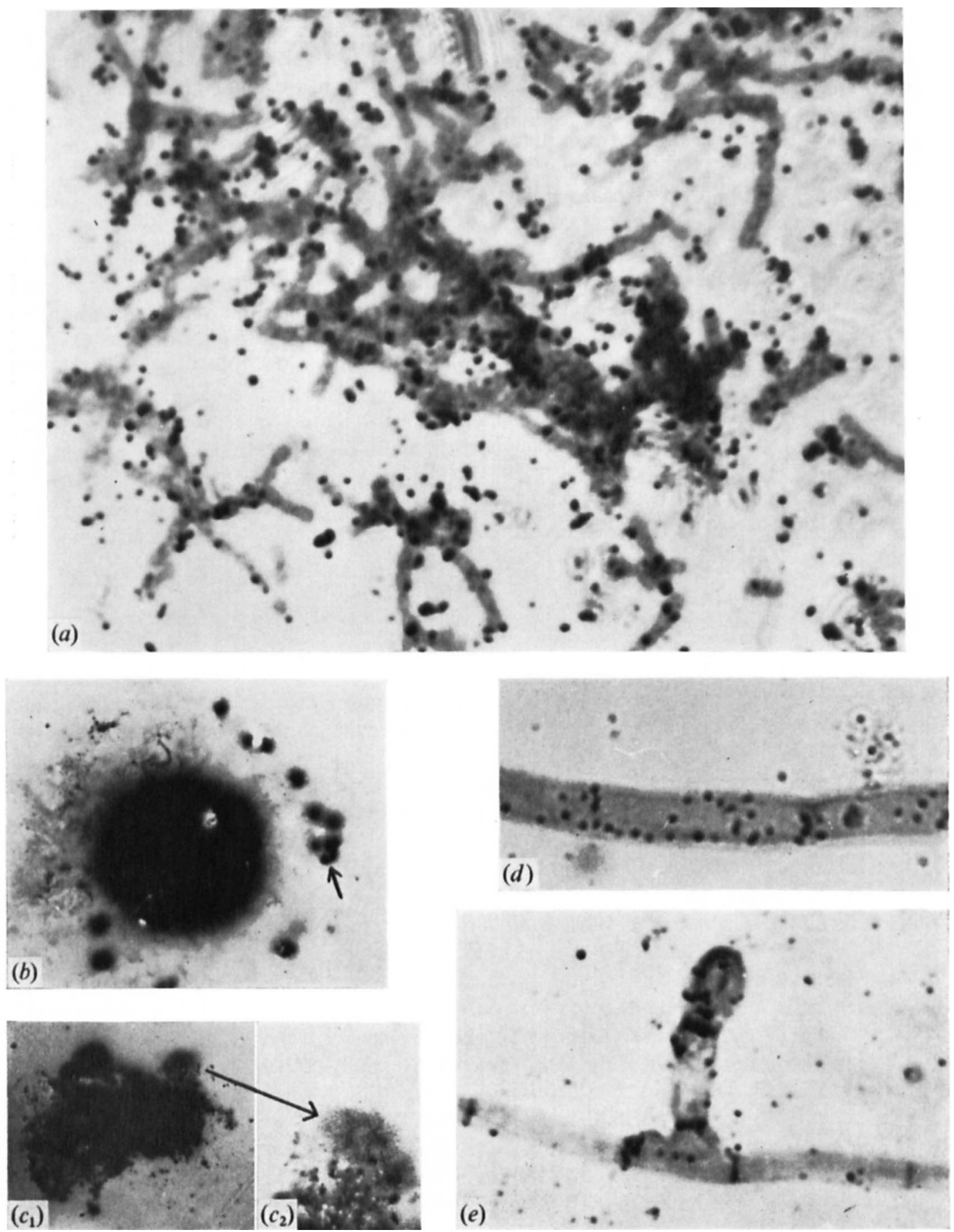
Non-sterile soil

The degradation of plant material placed on the surface of soil and the subsequent utilization of breakdown products were studied by two methods of autoradiography.

(I) Autoradiograms were prepared of the whole surface before incubation of the soils and at intervals after incubation at $25^{\circ}$ (Grossbard, 1969). The formation of radioactive colonies

Table I. Average numbers of silver grains in autoradiograms per spore of Trichoderma sp. that had been produced on gelatin-coated coverslips incubated for various periods in soil with ${ }^{14} \mathrm{C}$-labelled plant residues

\begin{tabular}{|c|c|c|c|}
\hline $\begin{array}{c}\text { Slide } \\
\text { no. }\end{array}$ & $\begin{array}{c}\text { Extent of } \\
\text { period of } \\
\text { incubation } \\
\text { (weeks) }\end{array}$ & $\begin{array}{l}\text { Average } \\
\text { count per } \\
\text { spore }\end{array}$ & $\begin{array}{l}\text { Average } \\
\text { count } \\
\text { per spore } \\
\text { (3 slides) }\end{array}$ \\
\hline $\left.\begin{array}{l}1 \\
2 \\
3\end{array}\right\}$ & 0 to $I^{\frac{1}{2}}$ & $\left\{\begin{array}{l}13.9 \\
12.7 \\
19.5\end{array}\right\}$ & 15.4 \\
\hline $\left.\begin{array}{l}4 \\
5 \\
6\end{array}\right\}$ & I $\frac{1}{2}$ to 6 & $\left\{\begin{array}{l}10.2 \\
15.6 \\
13.4\end{array}\right\}$ & I3.I \\
\hline $\left.\begin{array}{l}7 \\
8 \\
9\end{array}\right\}$ & 6 to 40 & $\left\{\begin{array}{l}17 \cdot 4 \\
14 \cdot 2 \\
1 \mathrm{I} \cdot 3\end{array}\right\}$ & $14 \cdot 3$ \\
\hline $\left.\begin{array}{l}10 \\
11 \\
12\end{array}\right\}$ & 40 to 48 & $\left\{\begin{array}{r}10 \cdot 8 \\
6 \cdot 3 \\
8.9\end{array}\right\}$ & $8 \cdot 6$ \\
\hline
\end{tabular}

Table 2. Radioactivity of the $\mathrm{CO}_{2}$ evolved during successive periods of incubation of pure cultures of an actinomycete and two fungi in soil containing ${ }^{14} \mathrm{C}$-labelled plant residues

$\begin{array}{cccc}\begin{array}{c}\text { Extent of } \\ \text { period of } \\ \text { incubation } \\ \text { (weeks) }\end{array} & \text { Streptomyces flavovirens } & \text { Rhizoctonia solani } & \text { Trichoderma sp. } \\ \text { o to } 6 & 75 & 60 & 54 \\ 6 \text { to } 40 & 12 & 8 & 7 \\ 40 \text { to II2 } & \text { Not detected } & \text { Not detected } & \text { Not detected }\end{array}$

* Expressed as a percentage of the original activity of the labelled plant material.

\section{Plate 2}

(a) Photomicrograph of a coverslip autoradiogram of Streptomyces flavovirens grown in sterile soil, conidial chains. $\times 3000$.

(b) Autoradiogram of a pellet of ground rye grass after 2 weeks incubation, showing radioactive hyphae and sclerotia of greater activity than the hyphae. $\times 2$.

$\left(c_{1}\right)$ Autoradiogram of a pellet of ground cocksfoot after II weeks of incubation showing a radioactive colony. $\times 1 \cdot 3$.

$\left(c_{2}\right)$ Enlargement of colony. $\times 2$.

Photomicrographs of coverslip autoradiograms on non-sterile soil.

(d) Hyphal fragment of an unidentified fungus on a coverslip $\mathrm{I} \mathrm{cm}$. from the edge of a pellet of cocksfoot. $\times 1500$.

(e) Non-sporing dark mycelium on a coverslip $\mathrm{I} \mathrm{cm}$. from a fragment of a rye leaf. $\times$ I 400 . 
and other structures was observed on the X-ray film by the naked eye. A pellet of rye grass was surrounded by a ring of fungal growth after 2 weeks of incubation; the corresponding autoradiogram (Pl. $2 b$ ) demonstrates the formation of radioactive hyphae that must have derived the ${ }^{14} \mathrm{C}$ from the pellet. Furthermore, autoradiographic images of sclerotia appear at 0.5 to $\mathrm{I} \mathrm{cm}$. from the edge of the pellet suggesting translocation of ${ }^{14} \mathrm{C}$ over a distance. The great density of the sclerotia is probably due to a preferential accumulation ${ }^{2}{ }^{14} \mathrm{C}$ constituents. The production of the sclerotia was accompanied by a fall in concentration of ${ }^{14} \mathrm{C}$ (Grossbard, 1969). It was sometimes possible to isolate and identify the specific fungi that incorporated nutrients from decaying plant residues. The position of a radioactive fungal colony adjacent to a disintegrating pellet of cocksfoot I I weeks after incubation was revealed by an autoradiogram of the whole soil surface ( $\left.\mathrm{Pl} .2 c_{1}\right)$. The colony of a non-sporing fungus with dark hyphae (Pl. $2 c_{2}$ ) and high cellulolytic activity adhered to the underside of the Melinex sheeting from which it was readily isolated.

(2) In the second method gelatin-coated coverslips were inserted into the soil surface, as in the sterile soil cultures, and were spaced around the plant material at distances of $\mathrm{I} \mathrm{cm}$. to the rim of the soil container. At monthly intervals the coverslips were replaced by new sets. Soil particles that adhered to the coverslips were removed and stored in sterile containers at $3^{\circ}$ to $4^{\circ}$. The coverslips were then fixed to microscope slides as described for sterile cultures, and autoradiograms prepared. Coverslips that had been near grass pellets $(\mathrm{Pl} 2 d)$ or fragments of intact rye leaves ( $\mathrm{Pl}$. 2e) showed autoradiograms of labelled spores as well as hyphae, some of which were hyaline and some dark. Some were clearly Basidiomycetes since clamp connexions were found, and some resembled non-sporing forms. Labelling of hyphae could be detected after 2 weeks of incubation and the frequency of strongly labelled hyphae reached a maximum after 2 to 3 months. The appearance of labelled structures was confined to coverslips situated at not more than $2 \mathrm{~cm}$. from the plant material and other structures were found that were not radioactive. Stored soil particles from coverslips which subsequently showed radioactive structures were plated out in an attempt to isolate and identify micro-organisms that resembled those appearing on the autoradiogram by comparing their morphological features. Rhizoctonia spp., Humicola grisea Traen, Fusarium spp. and Xylaria spp. were detected in this manner.

Both types of autoradiograms demonstrate the utilization and translocation of ${ }^{14} \mathrm{C}$ derived from the degradation of labelled plant materials in non-sterile soil.

\section{DISCUSSION}

The technique described here permits some distinction to be made between organisms participating primarily in the breakdown of a specific substrate and those which derive their nutrients from other sources.

The occurrence of enzymic breakdown of the radioactive plant tissues by the labelled organisms is indicated by the similarity of the autoradiographic images of microbial structures in sterile soil as compared with agar cultures. In the latter the sole source of carbon was the labelled plant residues, mainly crude cellulose, but in the soil many sources of carbon other than the labelled residues were available. Nevertheless, these were utilized by the three test organisms, indicating that they displayed a similar cellulolytic activity in sterile soil as they did on agar containing cotton or crude cellulose. This observation agrees with the findings of Garrett (1962) and supports the statement of Pugh (1964) 'that the ability of a fungus to decompose cellulose in the laboratory indicates that it must possess at least the potential to decompose this substrate in the soil'. 
In non-sterile soil primary degradation by the labelled micro-organisms is suggested since radioactive fungi were found only close to the labelled plant residues, and most of the active fungi appeared on the coverslips surrounding the plant fragments 2 months after incubation, corresponding to the time when a marked loss in the carbon constituents of the plant residues had occurred (Grossbard, 1969). It is unlikely that micro-organisms became radioactive by the incorporation of soluble ${ }^{14} \mathrm{C}$ compounds leached from plant material before its enzymic decomposition (Grossbard, 1969 ) or by such nutrients released by the activity of other micro-organisms. If this were the case then most furgal structures found in the same area should have been radioactive. However, labelled and unlabelled structures were frequently found on the same coverslip.

If many of the labelled organisms on the coverslips were primary agents in the enzymic breakdown of plant material then translocation of ${ }^{14} \mathrm{C}$ during growth must have occurred from the labelled residues incorporated in either agar or soil through the growing hyphae to reach the coverslip. Indeed, the effectiveness of the coverslip technique is dependent on a transport mechanism. The method is, therefore, most successful with fungi which grow extensively through agar and soil and have a more efficient translocation mechanism than have the actinomycetes where growth reached the coverslips only rarely. Translocation is especially evident in sterile soil cultures where the plant residues were mixed with the lower layers of soil. On the coverslip preparations in non-sterile soils translocation must have taken place over distances of at least $\mathrm{I} \mathrm{cm}$. for the ${ }^{14} \mathrm{C}$ compounds to reach the first coverslip near the plant material. Similarly, the autoradiograms of the whole soil surface demonstrated translocation of ${ }^{14} \mathrm{C}$ from the grass pellets into sclerotia 0.5 to $\mathrm{I} \mathrm{cm}$. away from the outer edge of the pellet.

The greater radioactivity of conidia, sclerotia and other resting structures compared with hyphae suggested accumulation of the tracer. This has been demonstrated previously with a variety of nuclides; some are those of normal constituents of fungi such as carbon $\left({ }^{14} \mathrm{C}\right.$; Grossbard, 1959) and phosphorus ( ${ }^{32} \mathrm{P}$; Wilcoxson \& Subbarayuda, 1968) but others are elements found in fungi only occasionally, namely cobalt and caesium $\left({ }^{60} \mathrm{Co}\right.$ and ${ }^{137} \mathrm{Cs}$; Grossbard, 1958).

A limitation of the stripping film technique of coverslip preparations in non-sterile soil is the difficulty of identifying accurately the labelled organisms, as the preparation of the autoradiogram may kill the micro-organisms. The group or genus involved can be deduced by the indirect methods described here or where the labelled mycelium has characteristic form. Nevertheless, the technique is a useful tool to demonstrate radioactivity of hyphal fragments in the soil in situ, and to provide some information on the utilization of specific substrates in the soil for resynthesis into cell material, i.e. incorporation into the biomass.

I wish to thank Professor N. A. Burges for valuable guidance in the work with non-sterile soil and for providing the facilities at the University of Liverpool; Dr R. D. Williams for constructive criticism of the manuscript; Mr G. E. Barton for essential collaboration; Mrs Glenys Wise, Mrs J. M. Martin and Miss Deanna Jackson for technical assistance; Professor A. E. Schwarting for the gift of the labelled rye; Dr M. V. Cheshire for estimating the specific activity of the rye; Imperial Chemical Industries for the gift of Melinex; and Professor E. Küster for the identification of the culture of Streptomyces flavovirens. 


\section{REFERENCES}

Buller, A. H. R. (1933). In Researches on Fungi, vol. 5. London, New York \& Toronto: Longman.

CAtch, J. R. \& Evans, E. A. (1960). Rate of formation of atropine in Atropa belladonna plants. Nature, London $\mathbf{1 8 8 , 7 5 8 - 7 5 9 .}$

Edelman, J., Shibko, S. I. \& KeYs, A. J. (1959). The role of the scutellum of cereal seedlings in the synthesis and transport of sucrose. Journal of Experimental Botany 10, 178-189.

EgGins, H. O. W. \& PuGH, G. J. F. (I962). Isolation of cellulose-decomposing fungi from the soil. Nature, London r93, 94-95.

GarretT, S. D. (1962). Decomposition of cellulose in soil by Rhizoctonia solani Kühn. Transactions of the British Mycological Society 45, I $15-120$.

GrossBaRD, E. (1958). Autoradiography of fungi through a layer of soil and in agar culture. Nature, London $182,854-856$.

Grossbard, E. (1959). In Experiments in Progress. Grassland Research Institute, Hurley 13, 69-70.

GrossbarD, E. (1962). Autoradiography of bacteria and Streptomycetaceae by the stripping film technique. Nature, London I93, 853-855.

Grossbard, E. (1969). A visual record of the decomposition of ${ }^{14} \mathrm{C}$-labelled fragments of grasses and rye added to soil. Journal of Soil Science 20, 38-5I.

Grossbard, E. \& Hall, D. M. (1962). Plant protein agar, a medium for the isolation and estimation of proteolytic organisms in grassland soils. Nature, London 196, $119-120$.

Grossbard, E. \& Stranks, D. R. (1959). Translocation of cobalt-60 and caesium-1 37 by fungi in agar and soil cultures. Nature, London 184, 310-314.

Hul, E. P. (1965). Uptake and translocation. In The Fungi, pp. 457-463. Edited by G. C. Ainsworth \& A. S. Sussmann. New York: Academic Press.

LUCAS, R. L. (1960). Transport of phosphorus by fungal mycelium. Nature, London 188, 763-764.

Paul, A. G., Scully, N. J. \& Schwarting, A. E. (1960). The biosynthesis of ${ }^{14} \mathrm{C}$-labelled ergot alkaloids. Journal of the American Pharmaceutical Association-Scientific Edition 49, 14-16.

PeLC, S. R. (1956). The stripping film technique of autoradiography. International Journal of Applied Radiation and Isotopes $\mathrm{I}, \mathrm{I} 72-\mathrm{I} 77$.

Pugh, G. J. F. (1964). An investigation of soil-borne cellulose-decomposing fungi in Greece. Annales de l'Institut Phytopathologique Benaki N.S. 7, 19-27.

Rogers, A. W. (1967). Techniques of autoradiography, pp. 246-25I. Amsterdam, London \& New York: Elsevier.

SchüTte, K. H. (1956). Translocation in the fungi. New Phytologist 55, I64-182.

SkINNER, F. A. (1960). The isolation of anaerobic cellulose-decomposing bacteria from soil. Journal of General Microbiology 22, 539-554.

Wilcoxson, R. D. \& Subbarayudu, S. (1968). Translocation to and accumulation of phosphorus-32 in sclerotia of Sclerotium rolfsii. Canadian Journal of Botany 46, 85-88.

Wilcoxson, R. D. \& SudiA, T. W. (1968). Translocation in fungi. Botanical Review 34, 32-5I. 